1 Associate Professor - School of Dentistry - UFAM - Univ. Federal do Amazonas, Manaus, AM, Brazil

${ }^{2}$ PhD Student - School of Dentistry - UNESP - Univ. Estadual Paulista, Araraquara, SP, Brazil

${ }^{3}$ Associate Professor - Centro Universitario de Ciencias de la Salud - Universidad de Guadalajara, Mexico

4 Associate Professor-School of Dentistry - UNESP - Univ. Estadual Paulista, Araraquara, SP, Brazil

${ }^{5}$ Full Professor - School of Dentistry - UNESP - Univ. Estadual Paulista Araraquara, SP, Brazil

Corresponding author:

Dr Gelson Luis Adabo

Department of Dental of Materials and Prosthodontics

School of Dentistry, UNESP - Univ. Estadual Paulista

Rua Humaita, 1680 - Araraquara,

Sao Paulo - 14801-903

BRAZIL

Fax: +55-16-3301-6406

E-mail: adabo@foar.unesp.br

Received: May 02, 2018

Accepted: December 18, 2018

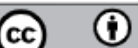

\section{Effect of zirconia substructure thickness on the mechanical properties and adhesion of veneering porcelain}

Daniel Lungareze ${ }^{1}$, Giovanni Cunha², Eduardo Mariscal Muñoz ${ }^{3}$, Renata Garcia Fonseca ${ }^{4}$, Gelson Adabo ${ }^{5,{ }^{*}}$

Aim: This study investigated the influence of yttrium-stabilized tetragonal zirconia polycrystals (Y-TZP) thickness on fracture load of porcelain-veneered crowns ( $F L)$, fracture toughness of porcelain (FT), and the shear bond strength zirconia/porcelain (SBS). Methods: Artificial first molar was prepared for full crown $(\mathrm{N}=45)$ with different occlusal reduction. Y-TZP cores were made with different thickness at the occlusal face $(1 \mathrm{~mm}, 2 \mathrm{~mm}$ and $3 \mathrm{~mm})(\mathrm{n}=15)$. The cores were veneered with VM9 - Vita porcelain with $1.0 \mathrm{~mm}$ layer. For FL testing, axial load was applied to the mesiolingual cusp of the crowns. For FT testing, flat Y-TZP plates ( 5 X5 mm) with 1,2 or $3 \mathrm{~mm}$ thickness were veneered with $1.0 \mathrm{~mm}$ porcelain layer $(n=10)$. FT by indentation fracture technique was measured close to the interface and at the top surface. For SBS by knife-edge shearing rod, cylindrical porcelain with $5 \mathrm{~mm}$ in diameter and $3 \mathrm{~mm}$ was applied on flat $Y$-TZP plates $(1,2$ and $3 \mathrm{~mm}$ thickness) $(n=10)$. Results: Data analyzed by 1-Way ANOVA for FL of crowns and SBS between Y-TZP and porcelain were not significant. Two-way ANOVA for FT was significant for zirconia thickness and measurement area. The post-hoc test showed higher values for the groups with 2 and $3 \mathrm{~mm}$, and higher values at the interface, irrespectively of Y-TZP thickness. Conclusion: The zirconia thickness did not affect the FL of veneered crowns and the SBS between the ceramics, but FT of porcelain was lower in thinner zirconia substructure and close to the interface Y-TZP/Porcelain.

Keywords: Zirconium. Dental porcelain. Fracture toughness. 


\section{Introduction}

The success of yttrium-stabilized tetragonal zirconia polycrystals (Y-TZP) for dental prosthesis relies on its high mechanical performance, biocompatibility and esthetics, and its use as substructure has been increased substantially in the last decade. Clinical studies have shown high survival rates of zirconia substructure, but chipping of veneering porcelain is the most common failure $e^{1-7}$. The survival rate of $93,2 \%$ was observed in crows and fixed partial dentures, made by Y-TZP framework, for period of $41,5+\_31,8$ months, the success rate was $81,63 \%$ with a minimum framework fracture of $2,7 \%^{8}$. Conversely, traditional porcelain fused to metal has shown survival rate of $97,6 \%$ against $95,2 \%$ for zirconia, in a 36,5+-6 months of evaluation ${ }^{4}$.

It is speculated that a possible cause of porcelain chipping in zirconia-based restorations is related to an improper core support to the porcelain, that is the weakest part of the system. The CAD-CAM coping design usually is made with a constant thickness once it is easier to fabricate, and it demands an inhomogeneous thickness of porcelain to build crown anatomy. However, thicker porcelain should be avoided because it may decrease the veneer mechanical resistance ${ }^{3,9-14}$. To reduce veneer chipping and delaminations it has been proposed a modified coping design for zirconia-core to provide a relatively constant space to the porcelain, improving the clinical performance of zirconia-based prosthesis ${ }^{4,9,11,14-18}$

Another issue is the relationship among thermal properties of Y-TZP and porcelain, which include coefficient of thermal expansion (CTE), thermal conductivity and diffusivity, and thermal tempering residual $\operatorname{stress}^{19}$. It was demonstrated that the CTE of porcelain must be lower than the substructure, but the mismatch must be minimum ${ }^{20}$. When the difference between CTE of core and veneer is negative, delamination of the veneer may occur. On the other hand, if the CTE of porcelain is much lower than Y-TZP core, cracks may initiate because of residual thermal stresses developed during cooling ${ }^{21}$. Y-TZP balance from temperature sintering to room temperature is slow, because it conducts heat substantially lower than veneer porcelain ${ }^{22}$. It results in temperature gradient during cooling, which is claimed as one of the causes for porcelain chipping ${ }^{23}$. These failures incidence is not found at the same rates in porcelain fused to metal prosthesis, possibly due to the higher thermal conductivity and mechanical properties of metals. The explanations based on the difference between properties of Y-TZP and metal substrates makes sense if it is considered that there is no significant difference among the mechanical properties of porcelain for metal or Y-TZP substructures ${ }^{20}$.

The residual thermal stresses exist irrespectively of external load and may be beneficial if it is a compressive tension, once it works against the initiation and the propagation of cracks. However, the compressive stresses are concentrated up to the deep of $16 \%$ of the thickness, while the internal bulk is under residual tension stress ${ }^{21}$. Thus, the residual stresses distribution change from the surface to the inner and it is generated by the thermal gradients that are driven by thermal properties of the ceramic materials, their thicknesses and cooling rate $21,24,25$. A slow cooling allows the relieve of part of the stresses above the porcelain $\mathrm{Tg}$ because of the viscoelastic behavior of 
the porcelain, but in a fast cooling rate the stress relaxation above the $\mathrm{Tg}$ is not complete, because the porcelain will stay in the viscoelastic state for a very short period ${ }^{19}$. On the other hand, slow cooling increases the risk of adhesive delamination ${ }^{26}$.

Taking into account that higher thickness of the anatomical core design may transfer heat slower than a thinner core, it is speculated if a slower cooling would have some effect on the veneer porcelain or adhesion between core and veneer. The aim of this study is to test the null hypothesis that there is no effect of Y-TZP thickness in: fracture load of veneered crowns; fracture toughness of veneer porcelain; and adhesion between $\mathrm{Y}$-TZP and porcelain.

\section{Materials and Methods}

\section{Fracture load of veneered crowns}

For the fracture load of veneered crowns, a impression (Impregum F, 3 M ESPE, Seefeld, Germany) was taken to reproduce an artificial upper first molar as a guideline for the tooth preparation, and as an index to aid the coping wax-up and porcelain stratification. To simulate anatomical design, three different occlusal reductions were made to produce core designs with variables thickness of $Y$-TZP, in which it would be applied a fixed thickness of veneer porcelain $(1.1 \mathrm{~mm})$. The tooth was prepared with a reduction with $1.2 \mathrm{~mm}$ proximal walls, 6 degrees of convergence angle and $1.0 \mathrm{~mm}$ deep chamfer. The occlusal surface reduction was $2.1 \pm 0.1 \mathrm{~mm}$, to produce space necessary for $1,0 \mathrm{~mm}$ Y-TZP core and $1.1 \mathrm{~mm}$ porcelain veneer. Subsequently, the occlusal reduction was increased to $3.1 \pm 0.1 \mathrm{~mm}(2.0 \mathrm{~mm} Y$-TZP core and $1.1 \mathrm{~mm}$ veneer). Additional $1 \mathrm{~mm}$ occlusal reduction was performed reaching $4.1 \pm 0.1 \mathrm{~mm}$ (3.0 $\mathrm{mm}$ Y-TZP core and $1.1 \mathrm{~mm}$ veneer). After each occlusal reduction it was taken impressions (Express XT - 3M ESPE) to reproduce the respective tooth preparations. The impressions were poured with Type IV gypsum (Elite Rock, Zermack) to produce the master dies for the groups G1 (1 mm occlusal core thickness), G2 (2 mm occlusal core thickness) and G3 (3 mm occlusal core thickness).

The dies were scanned by Ceramill Map400 (Amann Girrbach AG- Koblach, Austria). Wax patterns were carved to produce thickness of $0.6 \mathrm{~mm}$ in the axial walls, and different thickness in occlusal area: G1: $1 \mathrm{~mm} ; \mathrm{G} 2: 2 \mathrm{~mm} ; \mathrm{G} 3: 3 \mathrm{~mm}$. It allowed $1.0 \pm 0.1 \mathrm{~mm}$ of free space for the porcelain on the occlusal face in the three groups. A second scanning process was performed on the waxed dies to design the cores with different thickness at occlusal face in the software Ceramill Mind (Amann Girrbach) (Figure 1). The cores were milled in Ceramill Motion Inhouse machine (Amann Girrbach) in Y-TZP Ceramil ZI block (Amann Girrbach), which were sintered in Ceramill Therm oven (Amann Girrbach) according to the manufacturer's directions. Fifteen Y-TZP specimens were fabricated for each group.

The porcelain Vita VM9 (VitaZahnfabrik, BadSäckingen, Germany) was hand-made layered. The cores were steam-cleaned and a washbake firing was carried out. The powder base dentine (VM9) was mixed with Vita Modelling Liquid (VitaZahnfabrik) and the slurry was applied to the Y-TZP core driven by the silicone index, to standardize the crown anatomy and thickness of the veneer. A second porcelain firing was 


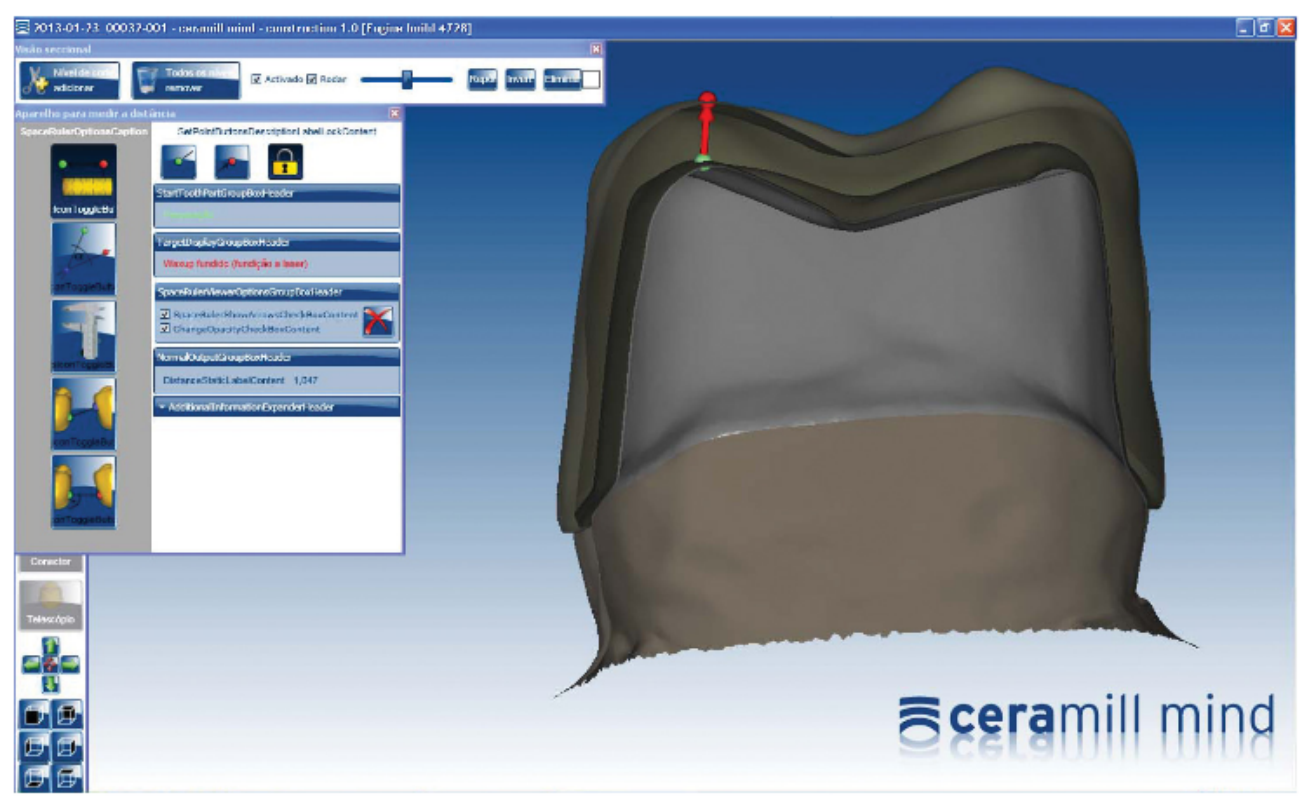

Figure 1. Example of the core with $1.0 \mathrm{~mm}$ thickness at occlusal face designed in the Ceramill Mind software

performed to correct the dental anatomy, and the glaze Vita Akzent (VitaZahnfabrik) was applied after finishing with diamond burs.

The internal part of the crowns was filled with epoxy resin with a $10 \mathrm{~mm}$ extension beyond to the marginal area that was embedded in a PVC ring. The compressive fracture load was applied on the mesiolingual cusp by means of $6 \mathrm{~mm}$ diameter stainless steel, in MTS Universal Mechanical Testing Machine Model 810 (Material Testing Systems, St. Paul, MN), at a rate of $1 \mathrm{~mm} / \mathrm{min}$ up to fracture. The failure modes were examined in stereomicroscope (M80; Leica Microsystems Ltd, Heerbrugg, Switzerland) at $\times 20$ magnification, and they were classified as cohesive, adhesive or combined. Fractured samples were analyzed under scanning electron microscope (Jeol JSM-7500F-SII, Sony, Japan).

\section{Apparent fracture toughness of the porcelain}

To the apparent fracture toughness of the porcelain by indentation fracture technique square plates ( $5 \times 5 \mathrm{~mm}$ ) of the Y-TZP (Ceramil ZI block - Amann Girrbach) were cut with 1,2 and $3 \mathrm{~mm}$ thicknesses, and the porcelain was applied with uniform thickness of $1.1 \mathrm{~mm}(\mathrm{~N}=30)$, following the firing procedures described before. The specimens were embedded in polymethyl methacrylate (PMMA) with a lateral face at the top surface. The specimens were ground in a polishing machine (Metaserv 2000, Buehler, Buehler UK Ltd., Coventry, United Kingdom) with sequential SiC paper up to \#4000-grit (Norton Abrasivos, Sao Paulo, SP, Brazil). Three indentations were made close to de interface $Y-T Z P /$ porcelain and three close to the top surface of porcelain, using a Vickers hardness tester Micromet 2100 series (Buehler, Lake Bluff, IL, USA), with $9.8 \mathrm{~N}$ load and $20 \mathrm{~s}$ dwell time. Fracture toughness was calculated according to the standard ASTM C 1421-99, based on the Vickers hardness number, length of the 
cracks growing from the indentation corners, and porcelain Young's modulus. The Young modulus of the porcelain VM9 was taken from Belli et al. ${ }^{20}$. The crack measurement was performed $30 \mathrm{~s}$ after the indentation to standardize the moment of crack growing. Fracture toughness calculation was carried out according the equation 1, where $\mathrm{K}_{\mathrm{IC}}$ is the fracture toughness (MPa. $\mathrm{m}^{1 / 2}$ ), $E$ is the Young modulus (GPa), $P$ is the hardness test load $(\mathrm{N}), \mathrm{H}$ is the Vickers hardness number $(\mathrm{VHN})$ and $\mathrm{C}$ is half of diagonal of indentation crack $(\mathrm{m})$. Mean values of three measurements at interface $\mathrm{Y}-\mathrm{TZP} /$ porcelain and porcelain surface were calculated for each specimen $(\mathrm{N}=30)$.

Equation 1

$$
K_{1 C}=0,016\left(\frac{E}{H}\right)^{\frac{1}{2}} \times\left(\frac{P}{C}\right)^{\frac{3}{2}}
$$

\section{Shear bond strength test}

Zirconia square samples ( $5 \times 5 \mathrm{~mm}$ ) with 1, 2 and $3 \mathrm{~mm}$ were prepared as described above. After wash bake layer firing, a cylindrical metal mold $(5 \mathrm{~mm}$ in diameter and $3 \mathrm{~mm}$ in height) was seated on the surface to build the porcelain layer following the technique described before $(n=10)$. After firing cycle, the Y-TZP segment of the specimen was embedded in PMMA, keeping the $\mathrm{Y}$-TZP/porcelain interface at the resin surface level. The shear bond strength test was performed at the interface by knife-edge shearing rod. Load was applied parallel to the long axis of the specimen in a universal testing machine (DL 2000, EMIC, São José dos Pinhais, PR, Brazil) - 5.0 kN load cell at a crosshead speed of $1.0 \mathrm{~mm} / \mathrm{min}$.

\section{Statistics}

Statistical analyses for fracture load of veneered crowns and shear bond strength were performed by one-way ANOVA $(\alpha<0.05)$. For fracture toughness two-way ANOVA was performed for the variables Y-TZP thickness and measurement region $(\alpha<0.05)$.

\section{Results}

The means and the standard deviations of fracture load of veneered crowns $(\mathrm{N})$ and shear bond strength (MPa) are shown in Table 1. One-way ANOVA for fracture load of veneered crowns was not significant $\left(F_{2,33}=0.556, p<0.58\right)$. Irrespectively of the core thickness all fractures were cohesive mode in the porcelain, with cracks initiating from the contact area (Figures 2, 3 and 4). One-way ANOVA for shear bond strength $\left(F_{2,27}=0.818, p<0.42\right)$, was not significant. The two-way ANOVA for fracture toughness (Table 2) was significant to the variables Y-TZP thickness and measurement region (close to the interface Y-TZP/porcelain or porcelain top surface), but it was not sig-

Table 1. Mean and the standard deviation of fracture load of veneered crowns and shear bond strength

\begin{tabular}{lccc}
\hline & G1 & G2 & G3 \\
\hline Fracture Load & $1979 \pm 486.3 \mathrm{~N}^{\mathrm{a}}$ & $2266 \pm 816.9 \mathrm{~N}^{\mathrm{a}}$ & $2316 \pm 672.9 \mathrm{~N}^{\mathrm{a}}$ \\
\hline Shear Bond Strength & $18.5 \pm 2.44 \mathrm{MPa}^{\mathrm{a}}$ & $15.6 \pm 3.80 \mathrm{MPa}^{\mathrm{a}}$ & $17.1 \pm 3.17 \mathrm{MPa}^{\mathrm{a}}$ \\
\hline * Same letter in row indicates no significant difference among groups $(\mathrm{p}<0.05)$. &
\end{tabular}




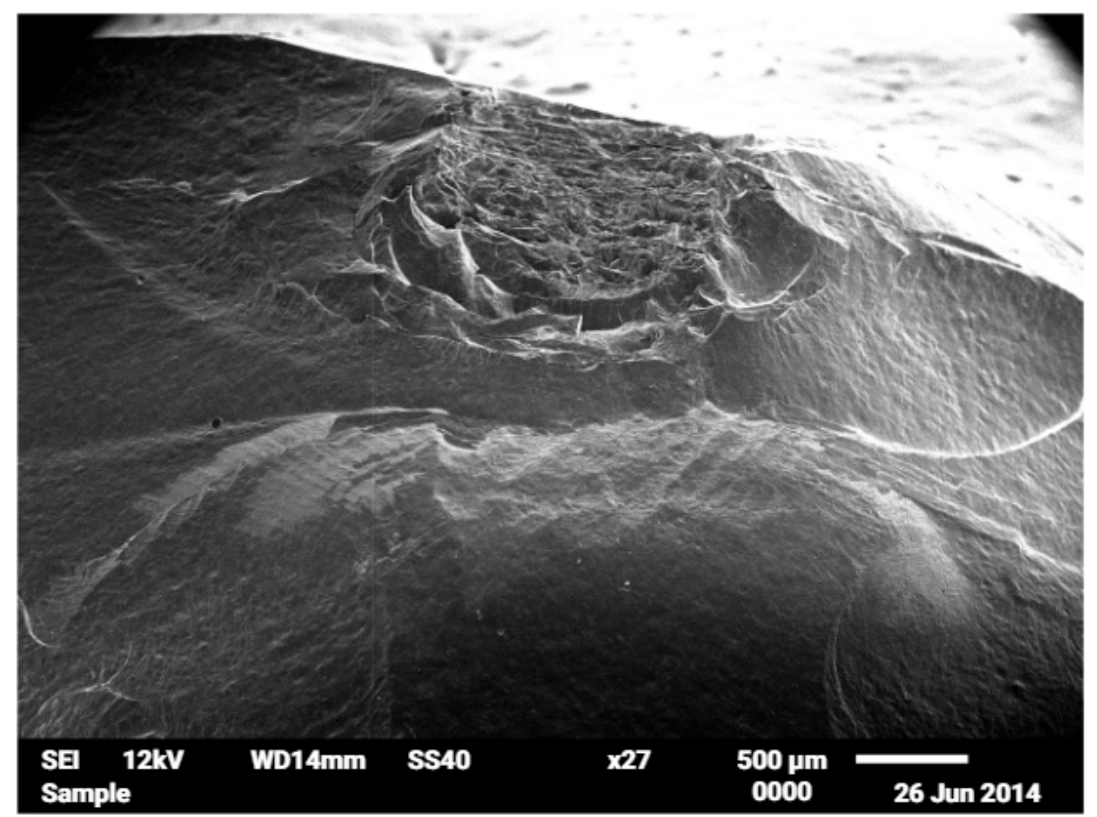

Figure 2. Scanning Electron Microscope image of fracture surface of veneered crown G1

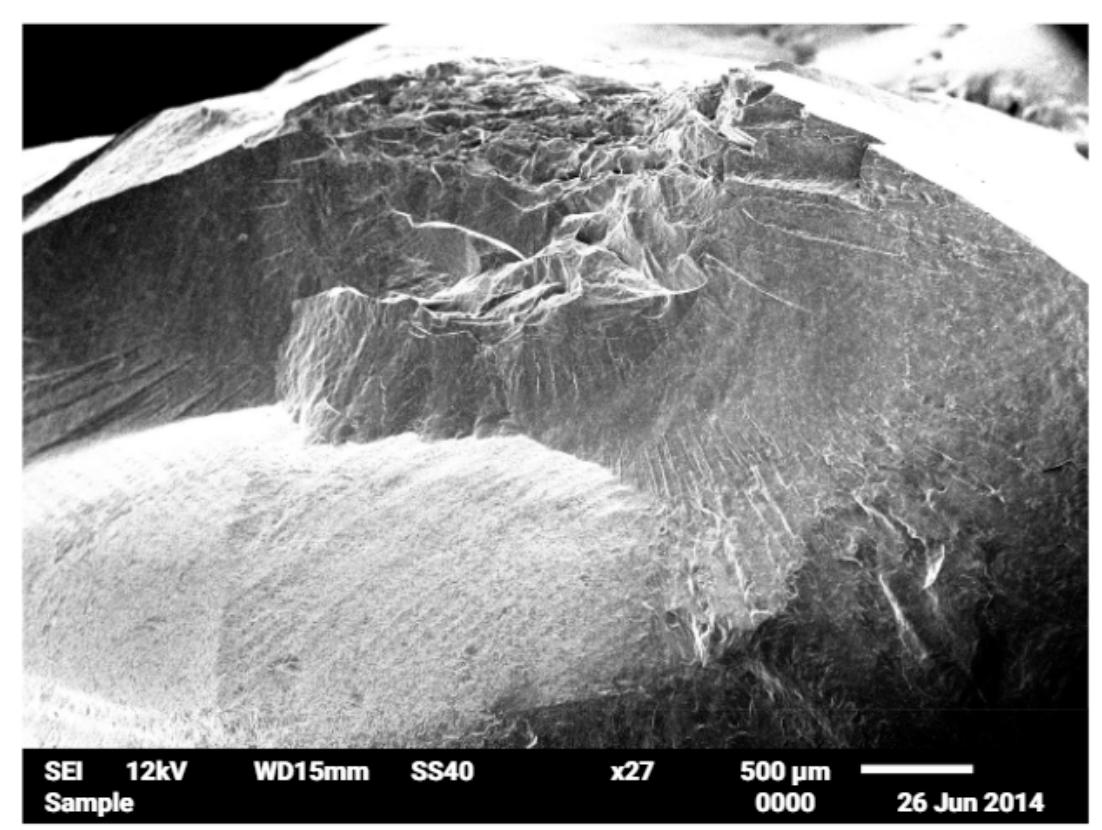

Figure 3. Scanning Electron Microscope image of fracture surface of veneered crown G2

nificant for the interaction $Y$-TZP thickness $X$ measurement region. For measurement region, $\mathrm{FT}$ at the top surface of porcelain was higher than at close to the interface Y-TZP/Porcelain. The post-hoc Tukey HSD test showed FT mean values of porcelain of the groups G2 and G3 were not different, but they were higher than that of the G1 (Table 3). 


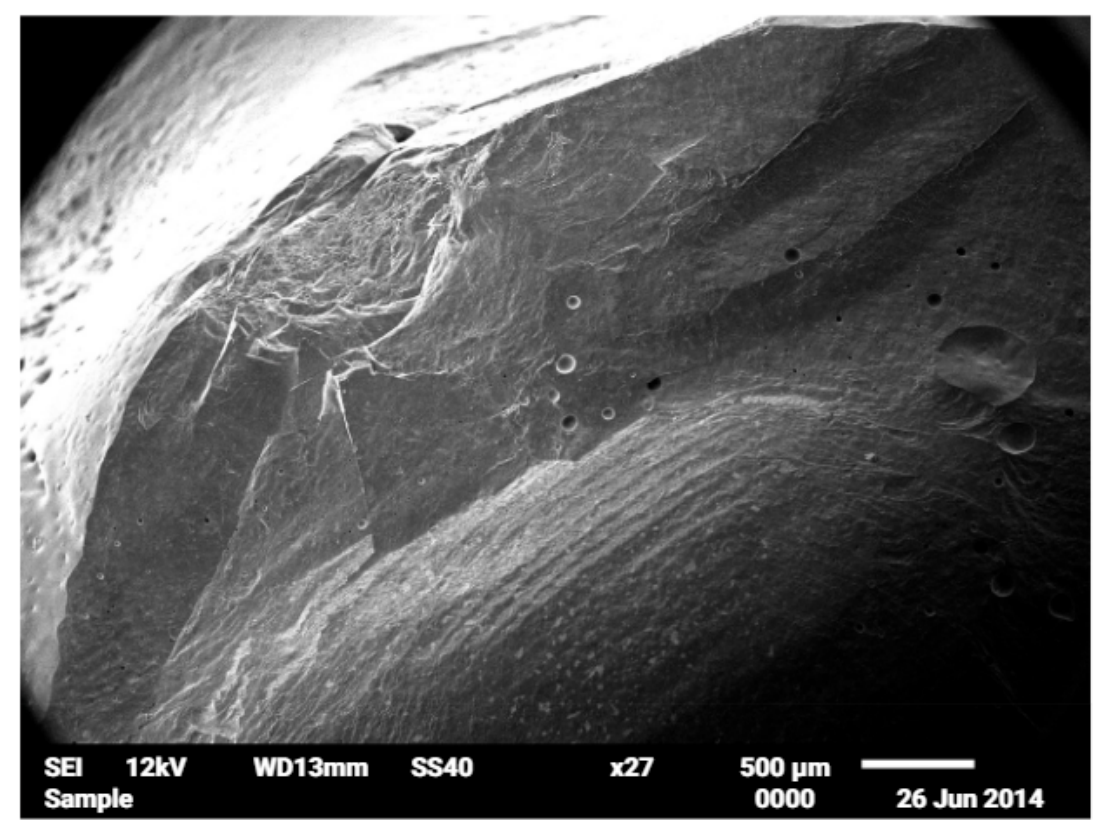

Figure 4. Scanning Electron Microscope image of fracture surface of veneered crown G3

Table 2. Two-way ANOVA for fracture toughness with respect to core thickness and measurement region variables

\begin{tabular}{lccccc}
\hline Source & $\begin{array}{c}\text { Type III Sum } \\
\text { of Squares }\end{array}$ & df & $\begin{array}{c}\text { Mean } \\
\text { Square }\end{array}$ & F & Sig. \\
\hline Y-TZP Thickness & 0.876 & 2 & 0.438 & 6.588 & 0.03 \\
\hline Measurement Region & 0.353 & 1 & 0.353 & 5.305 & 0.025 \\
\hline Interaction & 0.177 & 2 & 0.089 & 1.334 & 0.272 \\
\hline Error & 3.590 & 54 & 0.006 & & \\
\hline Total & 174.340 & 60 & & & \\
\hline Corrected Total & 4.996 & 59 & & & \\
\hline
\end{tabular}

Table 3. Mean and the standard deviation of Fracture Toughness (MPa.m ${ }^{1 / 2}$ ) of porcelain at interface Y-TZP/Porcelain and at the top surface of porcelain

\begin{tabular}{lcc}
\hline & Interface Y-TZP/Porcelain & Top surface of porcelain \\
\hline G1 & $1.53 \pm 0.19 \mathrm{MPa} \cdot \mathrm{m}^{1 / 2 \mathrm{aB}}$ & $1.49 \pm 0.22 \mathrm{MPa} \cdot \mathrm{m}^{1 / 2 \mathrm{bB}}$ \\
\hline $\mathrm{G} 2$ & $1.90 \pm 0.30 \mathrm{MPa} \cdot \mathrm{m}^{1 / 2 \mathrm{aA}}$ & $1.60 \pm 0.32 \mathrm{MPa} \cdot \mathrm{m}^{1 / 2 \mathrm{bA}}$ \\
\hline $\mathrm{G} 3$ & $1.84 \pm 0.29 \mathrm{MPa} \cdot \mathrm{m}^{1 / 2 \mathrm{aA}}$ & $1.72 \pm 0.19 \mathrm{MPa} \cdot \mathrm{m}^{1 / 2 \mathrm{bA}}$ \\
\hline
\end{tabular}

Same lowercase letter in row indicates no significant difference, and same uppercase in column indicates no significant difference $(p<0.05)$.

\section{Discussion}

The null hypothesis was partially accepted once the Y-TZP thickness did not influence the maximum fracture load of veneered crowns and bond strength between Y-TZP and porcelain. However, it was not accepted with regard to the fracture toughness of the porcelain because it varied according Y-TZP thickness, and measurement region. 
The expectation was that the different Y-TZP thicknesses could interfere in some properties of the porcelain because of the low thermal diffusivity and conductivity of Y-TZP. Mainjot et al. ${ }^{25}$ commented that during cooling the thermal gradient can exceed $200^{\circ} \mathrm{C}$ in samples with a typical thickness $(0.7 \mathrm{~mm})$ from the surface to the crown inner, and it is possible that the temperature may exceed the glass transition temperature $(\mathrm{Tg})$ of the veneer in some area, locking stresses into the porcelain ${ }^{21}$.

Non-anatomical core designs were not evaluated in this study, but the disadvantages of an inhomogeneous veneer layer are discussed by several authors $6,9,10,12,13,17,18,24$. A thicker porcelain layer may generate more intense residual stresses, because of the thermal properties of core and veneer, and the correspondent no uniform temperature gradients.

Irrespectively of the effects of those thermal gradients, a thick layer of the porcelain should be avoiding because it per se reduce the veneer resistance ${ }^{6,9,12,13,18}$, because if the veneer porcelain is thicker its brittleness may determine the chipping and fracture behavior ${ }^{11}$. It seems that it is consensual that an anatomical core design that keeps the porcelain layer uniform and adequately supported by the core is desirable, but the variation of core thickness introduces some new concerns, because thermal properties of the ceramics might generate different residual thermal stresses during cooling.

Few authors investigated the effect of the sub-structure thickness keeping a uniform porcelain layer to isolate this variable. The study of Mainjot et al. ${ }^{25}$ by hole-drilling method in bilayered disc with a standardized $1.5 \mathrm{~mm}$ thick veneering layer and variable zirconia framework thicknesses observed that the stress profile in the porcelain varies according to the zirconia thickness and cooling method. A thicker framework keeps the center of the porcelain hotter, generating tension from the periphery to the center, but the temperature distribution is complex, once it depends on other variables as cooling rate, materials thermal properties, firing equipment ${ }^{25}$. On the other hand, a computer simulation carried out by Silva et al. ${ }^{16}$ showed that in modified core design with higher thickness the stress is driven from the veneer to the core layer.

In the present study, the core thickness of the Y-TZP had no effect on the fracture load of veneered crowns, but fracture toughness was lower in the thinner $Y$-TZP specimens (group G1 - $1 \mathrm{~mm}$ ) and close to the interface porcelain/Y-TZP, irrespectively of the Y-TZP thickness. Tholey et al. ${ }^{23}$ studied cooling methods and uniform or anatomical frameworks by the quantification of the temperature. The authors commented that anatomical crown created greater thermal differences from the inner to the outer surface of veneer porcelain, but the differences were lower in slow cooling till $600^{\circ} \mathrm{C}$. It may be assumed that as thicker is the core slower is the cooling. Meira et al. ${ }^{19}$ showed that during a fast cooling the coefficient of thermal contraction of porcelain changes abruptly from the sintering temperature to $\mathrm{Tg}$, generating residual thermal stresses. Conversely, in a slow cool method, the stresses can be relieved due to the viscoelastic behavior of the porcelain above its $\operatorname{Tg}^{19}$. It could explain the differences of FT in the thinner Y-TZP group (G1). Since the cooling rate adopted in our study was not variable it can be assumed that thermal gradients in samples with variable volumes might had been different enough to impact in the residual thermal stresses ${ }^{20,22}$. 
In this study, all core designs can be considered as anatomical cores, and even at the minor thickness $(1 \mathrm{~mm})$ the resistance can be considered enough to support the veneer. Guess et al. ${ }^{9}$ observed that in crowns with anatomical design the fracture size was remarkably smaller likely because of the improvement of the porcelain support and the homogeneous core/veneer thickness ratios. In this scenario the veneer layer resistance is driven by its properties and geometric parameters, and the chipping runs within the porcelain layer leading a slight thin layer covering the framework ${ }^{23}$. Concerning to the fracture analysis, $100 \%$ of the fractured crowns were cohesive mode (Figure 2, 3 and 4 ). This fracture mode predominance is in agreement with other in vitro and clinical studies ${ }^{1-7}$.

As regards to adhesion between core and veneer, if it is considered that as thicker the core more heat it conserves and get longer to reach room temperature, the impact expected would be similar to slow cooling rate, but no effect was detected. Gostemeyer et al. ${ }^{26}$ discussed the negative effect of slow cooling rate on the adhesion between Y-TZP/porcelain, and explained that under slow cooling regimen a viscoelastic structural relaxation in the veneering porcelain occurs. The nature of the stress development (tensile or compressive) depends on the viscosity of the glass phase at a specific temperature and time for structural relaxation.

The contribution of this study is to show that anatomical core design is advantageous, because it guarantees a porcelain support decreasing risks of damage due the effect of the thermal properties of a thicker zirconia core. However, it is important to highlight limitations of this study. In spite of the values of fracture loads been higher those found in chewing function, caution is necessary in interpreting the significance of the results, once the methods do not reproduce clinical conditions, where mechanical and thermal fatigue phenomenon and chemical environment interact to create the complex scenario of mouth. Moreover, the study was designed for a unit crown for fracture load or geometric specimens for adhesion testing and fracture toughness. In a partial fixed prosthesis with high zirconia volume in the pontic and connectors' area may behave differently.

Within the limitations of this in vitro study, the significance of this study is that ticker Y-TZP core, as found in anatomical core design, does not impair fracture load of the veneer porcelain or on the adhesion between Y-TZP core and veneer. However, fracture toughness of the porcelain tends to increase when it is applied on thicker Y-TZP cores. Thus, considering that inhomogeneous veneer layer is not recommendable, this study reinforces the indication of anatomical core design.

\section{References}

1. Ortorp A, Kihl ML, Carlsson GE. A 5-year retrospective study of survival of zirconia single crowns fitted in a private clinical setting. J Dent. 2012;40(6):527-30. doi:10.1016/j.jdent.2012.02.011.

2. Raigrodski AJ, Yu A, Chiche GJ, Hochstedler JL, Mancl LA, Mohamed SE. Clinical efficacy of veneered zirconium dioxide-based posterior partial fixed dental prostheses: five-year results. J Prosthet Dent. 2012;108(4):214-22. doi:10.1016/S0022-3913(12)60165-6.

3. Rekow ED, Silva NRFA, Coelho PG, Zhang Y, Guess P, Thompson VP. Performance of dental ceramics: challenges for improvements. J Dent Res. 2011;90(8):937-52. doi:10.1177/0022034510391795. 
4. Rinke S, Schäfer S, Lange K, Gersdorff N, Roediger M. Practice-based clinical evaluation of metal-ceramic and zirconia molar crowns: 3-year results. J Oral Rehabil. 2013;40(3):228-37. doi:10.1111/joor.12018.

5. Sorrentino R, De Simone G, Tetè S, Russo S, Zarone F. Five-year prospective clinical study of posterior three-unit zirconia-based fixed dental prostheses. Clin Oral Investig. 2012;16(3):977-85. doi:10.1007/s00784-011-0575-2.

6. Heintze SD, Rousson V. Survival of Zirconia- and Metal-Supported Fixed Dental Prostheses: A Systematic Review. Int J Prosthodont 2010;23(6):493-503.

7. Sailer I, Gauckler LJ. Five-Year Clinical Results of Zirconia Frameworks for. Int J Prosthodont 2007;20(4):383-389.

8. Koenig V, Vanheusden AJ, Le Goff SO, Mainjot AK. Clinical risk factors related to failures with zirconia-based restorations: an up to 9-year retrospective study. J Dent. 2013 Dec;41(12):1164-74. doi: 10.1016/j.jdent.2013.10.009.

9. Guess PC, Bonfante E a, Silva NRF a, Coelho PG, Thompson VP. Effect of core design and veneering technique on damage and reliability of Y-TZP-supported crowns. Dent Mater. 2013;29(3):307-16. doi:10.1016/j.dental.2012.11.012.

10. Benetti P, Pelogia F, Valandro LF, Bottino MA, Bona A Della. The effect of porcelain thickness and surface liner application on the fracture behavior of a ceramic system. Dent Mater. 2011;27(9):948-53. doi:10.1016/j.dental.2011.05.009.

11. Alhasanyah A, Vaidyanathan TK, Flinton RJ. Effect of core thickness differences on post-fatigue indentation fracture resistance of veneered zirconia crowns. J Prosthodont. 2013;22(5):383-90. doi:10.1111/jopr.12016.

12. Hsueh $\mathrm{CH}$, Thompson GA, Jadaan OM, Wereszczak AA, Becher PF. Analyses of layer-thickness effects in bilayered dental ceramics subjected to thermal stresses and ring-on-ring tests. Dent Mater. 2008;24(1):9-17. doi:10.1016/j.dental.2006.12.009.

13. Wakabayashi N, Anusavice KJ. Crack Initiation Modes in Bilayered Alumina/Porcelain Disks as a Function of Core/Veneer Thickness Ratio and Supporting Substrate Stiffness. J Dent Res. 2000;79(6):1398-404. doi:10.1177/00220345000790060801.

14. Cho HY, Won HY, Choe HC, Son MK. Fracture Characteristics of Dental Ceramic Crown according to Zirconia Coping Design. Procedia Eng. 2011;10:1561-6. doi:10.1016/j.proeng.2011.04.261.

15. Kim JH, Park JH, Park YB, Moon HS. Fracture load of zirconia crowns according to the thickness and marginal design of coping. J Prosthet Dent. 2012;108(2):96-101. doi:10.1016/S0022-3913(12)60114-0.

16. Silva NRF, Rafferty BT, Zavanelli RA, et al. Conventional and Modified Veneered Zirconia vs Metalloceramic : Fatigue and Finite Element Analysis. J. Prosthodont. 2012;21(6):433-9. doi:10.1111/j.1532-849X.2012.00861.x.

17. Preis V, Letsch C, Handel G, Behr M, Schneider-Feyrer S, Rosentritt M. Influence of substructure design, veneer application technique, and firing regime on the in vitro performance of molar zirconia crowns. Dent Mater. 2013;29(7):e113-21. doi:10.1016/j.dental.2013.04.011.

18. Bonfante E a, Rafferty BT, Silva NRF a, et al. Residual thermal stress simulation in three-dimensional molar crown systems: a finite element analysis. J Prosthodont. 2012;21(7):529-34 doi:10.1111/j.1532-849X.2012.00866.X.

19. Meira JBC, Reis BR, Tanaka CB, et al. Residual stresses in Y-TZP crowns due to changes in the thermal contraction coefficient of veneers. Dent Mater. 2013;29(5):594-601. doi:10.1016/j.dental.2013.03.012.

20. Belli R, Frankenberger R, Appelt A, et al. Thermal-induced residual stresses affect the lifetime of zirconia - veneer crowns. Dent Mater. 2012:1-10. doi:10.1016/j.dental.2012.11.015. 
21. Swain M V. Unstable cracking (chipping) of veneering porcelain on all-ceramic dental crowns and fixed partial dentures. Acta Biomater. 2009;5(5):1668-77. doi:10.1016/j.actbio.2008.12.016.

22. Tan JP, Sederstrom D, Polansky JR, McLaren E a, White SN. The use of slow heating and slow cooling regimens to strengthen porcelain fused to zirconia. J Prosthet Dent. 2012;107(3):163-9. doi:10.1016/S0022-3913(12)60050-X.

23. Tholey MJ, Swain M V, Thiel N. Thermal gradients and residual stresses in veneered Y-TZP frameworks. Dent Mater. 2011;27(11):1102-10. doi:10.1016/j.dental.2011.08.001.

24. Guazzato M, Walton TR, Franklin W, Davis G, Bohl C, Klineberg I. Influence of thickness and cooling rate on development of spontaneous cracks in porcelain/zirconia structures. Aust Dent $\mathrm{J}$. 2010;55(3):306-10. doi:10.1111/j.1834-7819.2010.01239.x.

25. Mainjot AK, Schajer GS, Vanheusden AJ, Sadoun MJ. Influence of zirconia framework thickness on residual stress profile in veneering ceramic: measurement by hole-drilling. Dent Mater. 2012;28(4):378-84. doi:10.1016/j.dental.2011.11.009.

26. Göstemeyer G, Jendras M, Dittmer MP, Bach F-W, Stiesch M, Kohorst P. Influence of cooling rate on zirconia/veneer interfacial adhesion. Acta Biomater. 2010;6(12):4532-8. doi:10.1016/j.actbio.2010.06.026. 